\title{
Coeducación: un reto para las escuelas del siglo XXI
}

Coeducation: a challenge for schools of the 21st century

\section{Resumen}

Ana Isabel Ugalde Gorostiza iD

e-mail: anaisabel.ugalde@ehu.eus

Euskal Herriko Unibertsitatea. España

Pilar Aristizabal Llorente

e-mail: p.aristizabal@ehu.eus

Euskal Herriko Unibertsitatea. España

Beatriz Garay Ibañez de Elejalde

e-mail: beatriz.garai@ehu.eus

Euskal Herriko Unibertsitatea. España

Haritz Mendiguren Goienola

e-mail: hamengoi@gmail.com

Euskal Herriko Unibertsitatea. España

Ante la persistencia de las desigualdades entre mujeres y hombres, la coeducación es un reto para el sistema educativo actual. El objetivo de este estudio es conocer la situación de los centros de Vitoria-Gasteiz en relación a la coeducación. Igualmente se pretende analizar en qué medida son conocidas en los centros las políticas coeducativas y su incidencia en el día a día en la escuela. Para una primera aproximación a la realidad educativa estudiada, se pasaron dos cuestionarios realizados ad hoc uno de ellos dirigido al profesorado y el otro, a los equipos de dirección de los centros. Respondieron al cuestionario un total de 419 personas pertenecientes a 30 centros de la ciudad. Posteriormente, se realizaron 7 grupos de discusión: dos con profesorado, tres con alumnado y dos con familias; en total, 51 personas. Una de las conclusiones más relevantes del estudio es que existen numerosos programas destinados a trabajar la coeducación y que son conocidos por la comunidad educativa, pero su impacto no es el deseado. En los centros que se encuentran más cerca de la coeducación plantean la necesidad de estructurar su proyecto coeducativo más allá de campañas y de la celebración de días puntuales. Además, proponen abordar necesidades como la formación en género, la introducción de contenidos coeducativos en el curriculum, la elección y preparación de materiales adecuados y, por último, el trabajo colaborativo y coordinado de las instituciones que trabajan en favor de la igualdad.

Palabras clave: coeducación; igualdad de oportunidades; política de la educación; sistema educativo; sexismo.

\begin{abstract}
Given the fact that inequalities between women and men still persist, nowadays coeducation remains a challenge for educational systems. The purpose of this study is getting to know how coeducation is handled in the schools of Vitoria-Gasteiz. Likewise, it aims to analyze how far coeducational policies are known in the educational centers and their influence in the schools' daily life. In order to get a first approach of the educational reality under study, ad hoc questionnaires were carried out, one addressed to teachers, and the other to members of the schools' head teaching team. 491 members of 30 local schools answered the questionnaire. Later on, 7 focus groups were held: two of them aimed to teachers, three to students, and two to families; in total, 51 persons took part. One of the most relevant conclusions of this piece of research is that there are numerous programs aiming to work on coeducation, and they are well known by the studied educational communities, however they have not achieved the desired impact. Those schools closer to coeducation address the need to establish a coeducational project that goes further than campaigns and punctual celebration days. In addition, they propose to tackle several needs, like training on gender, introducing coeducational contents in the curriculum, selection and preparation of adequate material and, finally, collaborative and coordinated work among the institutions which work in favor of equality.
\end{abstract}

Keywords: coeducation; equal opportunities; educational policy; educational system; sexism.

Recibido / Received: 20-01-2019

Aceptado / Accepted: 02-04-2019

Publicación en línea / Published online: 01-07-2019

Cómo referenciar este artículo / How to reference this article:

Ugalde Gorostiza, A. I., Aristizabal LLorente, P., Garay Ibañez de Elejalde, B., \& Mendiguren Goienola, H. (2019). Coeducación: un reto para las escuelas del siglo XXI. Tendencias Pedagógicas, 34, pp. 16-36. doi: $10.15366 /$ tp2019.34.003 


\section{Introducción}

La coeducación sigue siendo un desafío para la escuela, a pesar del largo camino recorrido y de las numerosas leyes dictadas en favor de la igualdad. Diferentes estudios realizados en los últimos años muestran la persistencia de las desigualdades entre mujeres y hombres. La discriminación no afecta a sus resultados escolares, pues las mujeres obtienen calificaciones superiores a las de los hombres $\mathrm{y}$, sin embargo, sufren mayores tasas de desempleo, perciben un salario inferior en algunos empleos y se enfrentan a mayores dificultades para acceder a puestos de prestigio (Barbieri et al., 2017; Calatrava, 2013; Informe GENET, 2015). Todo ello limita sus oportunidades, afectando a su bienestar y al conjunto de su vida pública y privada (Suberviola, 2012; Subirats, 2016).

Para avanzar y poner fin a las desigualdades, las miradas se dirigen a la escuela, donde rigen, entre otros, el principio de igualdad de oportunidades y el derecho a la educación, pero en el caso de las mujeres siempre han sido posteriores y secundarios con respecto a los hombres, y «ello porque nuestra sociedad ha sido y, con otras manifestaciones, [la escuela] sigue siendo sexista, desde un planteamiento cultural y económico» (Madrid \& Lucer, 2010, p.225). Urruzola, (1995) señala que, una escuela verdaderamente coeducadora debe:

«educar a las chicas y a los chicos, al margen del género femenino y masculino, es decir, educarles partiendo del hecho de la diferencia de su sexo, potenciando el desarrollo de su individualidad, pero sin tener en cuenta los roles que se les exige cumplir desde una sociedad sexista, por ser de uno u otro sexo» (p. 267).

Pero ¿̇es la escuela actual coeducadora?

\subsection{Abundancia de programas coeducativos vs. escasa incidencia en los centros}

Dada la distancia entre las leyes y la consecución de los derechos que en ellas se recogen (Aristizabal, 2011; Madrid \& Lucer, 2010), para avanzar en la buena dirección han proliferado en los últimos años proyectos orientados a construir una escuela coeducativa.

Desde las Consejerías de Educación autonómicas y Organismos de la Mujer se han diseñado programas dirigidos a profundizar en ese modelo de escuela, a prevenir la violencia de género o a promover la educación afectivo-sexual. En 2005, por iniciativa del Ministerio de Igualdad, a través del Instituto de la Mujer y del Ministerio de Educación, se crea la Red Intercambia cuyo objetivo es «favorecer la puesta en común de todas las experiencias educativas, proyectos y materiales a favor de la igualdad de mujeres y hombres, que han sido desarrollados por las Consejerías de Educación y Organismos de igualdad autonómicos» (Torres \& Miguel, 2010, p. 27). De las propuestas recopiladas en Intercambia, hemos analizado los principales programas que se abordan en las Comunidades Autonómas de Andalucía, Canarias, Asturias, Cataluña y Navarra.

\subsubsection{Programas dirigidos a profundizar en el modelo coeducativo de escuela}

Asturias, Cataluña y Navarra cuentan con una red telemática para promover la coeducación y la prevención de la violencia sexista en las aulas. En Cataluña, por ejemplo, a través del portal del Departamento de Educación de la Generalitat, se ofrecen reflexiones, recursos pedagógicos, materiales didácticos, artículos y enlaces a sitios web, para trabajar en las diferentes etapas educativas desde una perspectiva igualitaria. Es de reseñar la guía de coeducación para los centros educativos, donde se recogen pautas de reflexión y recursos para la elaboración de un proyecto de centro con perspectiva de género (Roset, Pagés, Lojo, y Cortada, 2008).

En Asturias, el departamento de educación mantiene la red telemática Coeducación. Espacio para educar en igualdad en la que destacan dos programas, cuyo objetivo es facilitar tanto al alumnado como al profesorado el desarrollo de contenidos coeducativos en diferentes áreas curriculares. Uno de ellos en Primaria, Yo cuento, tú pintas, ella suma (2018-2019) y el otro en Secundaria, ESO por la Salud que busca incorporar contenidos de salud y coeducación en las áreas de Ciencias de la Naturaleza, Educación Física, Inglés, Lengua y Literatura, Ciencias Sociales, Matemáticas y Educación para la Ciudadanía. Promueve también el Proyecto Iguales, un programa de la Radiotelevisión del principado de Asturias (RTPA) sobre la igualdad entre hombres y mujeres, un espacio para reflexionar 
sobre la igualdad de género en la sociedad asturiana, y para promover la prevención de la violencia machista. El programa está protagonizado por escolares, maestras y maestros, filósofas y mujeres referentes en muchos campos. Participa en el mismo la filósofa Amelia Valcárcel, con su sección Sabias qué, para recordar el papel de muchas mujeres olvidadas por la historia. También llevan a cabo el programa Rompiendo esquemas (2007), para ayudar en la toma de decisiones académicoprofesionales, con autonomía y sin estereotipos vinculados al sexo. Igualmente cuenta con el Proyecto piloto de Coeducación (2018), que en su primera fase pretende analizar los espacios de relación donde niñas y niños interactúan «libremente», principalmente, el patio.

En Canarias se ha puesto en marcha el Programa Educar para la igualdad (2018), cuyo fin es propiciar que toda la comunidad educativa trabaje y se relacione desde una perspectiva coeducativa, para superar los estereotipos sexistas, potenciar unas relaciones igualitarias y prevenir la violencia de género. Navarra cuenta con el blog Coeducando. Un espacio que facilita apoyo al profesorado para trabajar la coeducación. Se pueden encontrar recursos, materiales didácticos, experiencias y cursos de formación.

\subsubsection{Programas educativos dirigidos a prevenir la violencia de género}

Para estos programas, Grañeras, Mañeru, Martín Sánchez, De La Torre, \& Alcalde (2007) revisan las principales investigaciones, estudios e informes publicados sobre dicha problemática hasta el año 2007.

En las Comunidades que estamos estudiando son más recientes propuestas como la campaña andaluza Si es amor, cuyo objetivo es fomentar relaciones igualitarias entre la juventud, mediante la difusión de modelos positivos. Paralelamente, destaca No es amor, que detalla las principales claves para detectar la violencia en las relaciones sentimentales y utiliza las redes sociales para su difusión.

En Canarias desarrollan Sin Machismo, sí, para la prevención de la violencia machista. Consta de Apps para detectar el sexismo y proporcionar herramientas para analizar las relaciones establecidas entre la población juvenil. Asimismo, aporta direcciones donde acudir o solicitar información o ayuda. Otra oferta la constituye EnrédateSinMachismo.com, dirigida a prevenir, sensibilizar e informar sobre la violencia de género a jóvenes. Se orienta a promover relaciones igualitarias entre chicos y chicas.

En Asturias el programa Identidades Digitales busca evitar situaciones de violencia por vías telemáticas, incitando a navegar de manera segura.

En Cataluña jAmar no duele! es un programa también dirigido a la población adolescente con el mismo fin.

El Programa Nahiko del País Vasco lo hace desde el respeto y la no violencia, impulsando la convivencia en igualdad, mediante la educación en valores, basándose en los derechos humanos y el análisis de los roles de género.

\subsubsection{Programas que trabajan las relaciones afectivo-sexuales}

Existe una gran variedad de programas dirigidos a trabajar las relaciones afectivo-sexuales, como la App Detect Amor, desarrollada a partir de la investigación Andalucía Detecta. Se dirige a jóvenes, para que reflexionen acerca de sus ideas sobre el amor, las relaciones de pareja, etc.

El programa asturiano de Educación afectivo-sexual, conducente a promover un desarrollo sano del alumnado, incluye diversas acciones, materiales didácticos y de evaluación. Asimismo, Ni ogros ni princesas está orientado a proporcionar una formación afectivo-sexual adolescente basada en la salud y el placer, en el fomento de la autoestima y la autonomía, en la libertad de elección desde el conocimiento, en la igualdad de mujeres y hombres, y en el respeto a las diferentes orientaciones sexuales.

En el País Vasco, Sехитихи es una propuesta interactiva basada en nuevas tecnologías, dirigida al alumnado de tercero y cuarto de la ESO. Su objetivo principal es favorecer la adquisición de competencias que ayuden a la población adolescente a manejar sus necesidades afectivo-sexuales. En su sitio web ofrece material para el profesorado y familias. Fue galardonado con el premio a la excelencia e innovación en programas gubernamentales de educación sexual por World Association for Sexual Health (WAS) (2013). 


\subsubsection{Propuestas relacionadas con celebraciones periódicas}

Además de los programas detallados, numerosas iniciativas se desarrollan en días señalados como el 8 de marzo, Día Internacional de la Mujer, y el 25 de noviembre, Día Internacional contra la Violencia hacia las Mujeres. Las actividades específicas de dichas fechas constituyen los hitos de la coeducación en muchos centros.

Sin intención de profundizar, destacamos en Andalucía el programa Muro contra la violencia sexista, que abre la posibilidad a escuelas y organizaciones diversas de publicar comentarios, fotos, vídeos y recursos educativos. La campaña Suma tu voz trata de implicar y hacer cómplice a toda la ciudadanía en la lucha contra la violencia de género. Pone el énfasis en la participación a través de colectivos profesionales, institucionales, sociales y culturales. La campaña La violencia no es un juego ofrece talleres dirigidos al alumnado de Infantil y Primaria para promover la sensibilización y prevención de la violencia contra las Mujeres.

En Cataluña destaca el Concurso de micro-relatos 420 caràcters per a la igualtat. La iniciativa Tú mueves ficha. Cataluña por la equidad de género promueve la reflexión y la revisión individual en torno al concepto de equidad de género en el ámbito profesional, familiar y personal. Además, el Día Internacional de las Mujeres, la Generalitat, las cuatro Diputaciones, la Asociación Catalana de Municipios y la Federación de Municipios de Cataluña divulgan una campaña unitaria institucional de sensibilización.

El Instituto Vasco de la Mujer -Emakunde- desarrolla anualmente campañas en torno al 8 de marzo. Asimismo, BeldurBarik (Sin miedo), impulsada por la red de municipios vascos Berdinsarea, es una iniciativa para el 25 de noviembre. Fomenta la igualdad, el respeto, la autonomía y la libertad entre la juventud. Brinda materiales didácticos en formato digital, papel y audiovisual, y herramientas de comunicación, como spots y espacios de debate sobre los mismos.

\subsection{Claves para elaborar el Proyecto Coeducativo de centro}

Estos programas y campañas no parecen ser suficientes. Se necesitan propuestas globales que impliquen a toda la comunidad educativa y recojan los presupuestos y estudios de la coeducación. Tomé (2017) la reivindica como futuro modelo de vida escolar y sostiene que la elaboración de Proyectos Coeducativos de centro es otro de los retos planteados para avanzar hacia la Igualdad. Para ello, resulta imprescindible implicar a toda la comunidad educativa: profesorado, alumnado, familias representantes municipales, personal no docente y consejo escolar, procurando la participación de ambos sexos (Suberviola, 2012; Tomé, 2017).

En Navarra, El Plan de Coeducación 2017-2021 para los centros y comunidades educativas de Navarra (Gobierno de Navarra, 2017), recoge propuestas encaminadas en esa dirección.

El Plan de Coeducación 2017-2021 del Departamento de Educación navarro ha comenzado con Skolae, curso piloto acogido duramente por algunos sectores de la comunidad foral. Es una propuesta:

«para la adquisición progresiva de las competencias básicas que permitirán a las niñas y a los niños elegir, construir y vivir el proyecto vital propio desde el conocimiento, la libertad y la capacidad de decidir sobre su futuro sin condicionantes de género, aprendiendo a identificar las desigualdades, a luchar contra ellas y a ejercer su derecho a la igualdad en el ámbito de su cultura, religión, clase social, situación funcional, etc.» (p.8).

El Plan recoge 4 aprendizajes y 4 competencias a desarrollar en la escolaridad obligatoria, Bachillerato y Módulos Profesionales (figura 1), así como una secuenciación por etapas educativas y orientaciones para desarrollarlo. 
Figura 1.

Aprendizajes y competencias relacionadas con la coeducación a desarrollar en el sistema educativo

\begin{tabular}{|c|c|}
\hline APRENDIZAJES & COMPETENCIAS \\
\hline $\begin{array}{l}\text { 1. CRÍTICA Y RESPONSABILIDAD FRENTE A } \\
\text { LA DESIGUALDAD }\end{array}$ & $\begin{array}{l}\text { - Identificar y analizar las desigualdades de género existentes y } \\
\text { responsabilizarse para enfrentarse a ellas y transformarlas. }\end{array}$ \\
\hline $\begin{array}{l}\text { 2. AUTONOMÍA E INDEPENDENCIA } \\
\text { PERSONAL }\end{array}$ & $\begin{array}{l}\text { - Asumir los trabajos de cuidado y del empleo como base para la } \\
\text { autonomía y la independencia en proyectos de vida } \\
\text { igualitarios. }\end{array}$ \\
\hline $\begin{array}{l}\text { 3. LIDERAZGO, EMPODERAMIENTO Y } \\
\text { PARTICIPACIÓN SOCIAL }\end{array}$ & $\begin{array}{l}\text { Reconocer la capacidad propia para tomar decisiones e } \\
\text { impulsar la actuación conjunta en la consecución de objetivos } \\
\text { comunes. }\end{array}$ \\
\hline 4. SEXUALIDAD Y BUEN TRATO & $\begin{array}{l}\text { - Conocer y aceptar la capacidad personal para expresar y } \\
\text { establecer relaciones afectivas, sexuales y de convivencia } \\
\text { favorecedoras del respeto y el crecimiento personal en } \\
\text { igualdad. }\end{array}$ \\
\hline
\end{tabular}

Fuente: Plan de Coeducación 2017-21. Gobierno de Navarra (2017, p.16)

Este plan destaca como retos del sistema educativo la necesidad de trabajar la igualdad de derechos e identificar las desigualdades de género; valorizar todo lo relacionado con los cuidados, la autonomía e independencia personal; orientar al alumnado en la toma de decisiones y ayudarle a elegir su itinerario vital sin condicionamientos de género; prevenir la violencia de género y educar en el respeto a la diversidad de sexo, género y opciones sexuales. Todos ellos constituyen los presupuestos fundamentales sobre los que se sostiene en la actualidad el quehacer de la coeducación. Igualmente importante es la visibilización y puesta en valor de los saberes femeninos en el currículum, porque lo que no se ve no existe.

En el contexto actual, con la escuela segregada consagrada por la LOMCE (Ley Orgánica 8/2013), que en su artículo 84.3 dice que «no constituye discriminación la admisión de alumnos y alumnas o la organización de la enseñanza diferenciadas por sexos» y que «la enseñanza diferenciada por sexos no implicará obstáculos a la hora de suscribir conciertos con las Administraciones educativas» y que cuenta con el aval del Tribunal Constitucional, quien considera que dicho artículo no causa discriminación (TC 31/2018 de 10 de abril); y con opciones políticas denostando los avances conseguidos en la lucha por la igualdad de las mujeres, es más necesario que nunca estar alerta y no permitir retroceso alguno. Como afirmó Simone de Beauvoir (1908-1986), «No olvidéis jamás que bastará una crisis política, económica o religiosa para que los derechos de las Mujeres vuelvan a ser cuestionados. Esos derechos nunca se dan por adquiridos. Debéis permanecer vigilantes durante toda vuestra vida».

\title{
1.3. Políticas para la igualdad en el ámbito educativo de la CAPV
}

Pero no todo son malas noticias, para el Departamento de Educación de la Comunidad Autónoma del País Vasco (CAPV), uno de los ejes prioritarios en el sistema educativo es la coeducación.

El Plan Director para la Coeducación y Prevención de la violencia de género en el sistema educativo (2013) recoge como finalidad:

\begin{abstract}
«garantizar un modelo de escuela coeducativa basada en el desarrollo integral de las personas, al margen de los estereotipos y roles en función del sexo; que eduquen en el rechazo a toda forma de discriminación y violencia de género, y que posibilite una orientación académica y profesional no sexista; contando con la participación y la implicación de todas las personas de la comunidad educativa» (p. 40).
\end{abstract}

El plan plantea 5 compromisos y cinco desafíos para alcanzar una escuela coeducativa (p. 43-44). Los compromisos son: 
1. Sensibilizar al profesorado en materia de coeducación, diversidad afectivo-sexual y prevención de la violencia de género. Para lo cual la administración organizará seminarios, cursos, orientaciones, directrices...

2. Formación específica a un número significativo de centros escolares para iniciar y/o desarrollar procesos de transformación de la escuela mixta a la escuela coeducativa y preventiva de la violencia de género.

3. Desarrollo de proyectos integrales en diez centros piloto, para que puedan servir de modelo y referencia a otros centros educativos de la CAPV.

4. Nombramiento de profesorado responsable de coeducación en los centros escolares.

5. Nombramiento de personas responsables de coeducación y prevención de la violencia de género en cada uno de los servicios estratégicos del Departamento (Servicio de Apoyo al profesoradoBerritzegune, Dirección de Innovación, Inspección Educativa, ISEI-IVEI).

$\mathrm{La}$ «figura responsable de igualdad» en los centros educativos, del cuarto compromiso, es clave para el desarrollo de estos acuerdos. Esta figura aparece por primera vez en España en la Ley contra la violencia de género (Ley 1/2004) y es incluida posteriormente en la Ley Orgánica 2/2006, de 3 de mayo, de Educación (LOE, 2/2006).

La LOE (art. 126 y 127) regula esta figura en los centros escolares, estableciendo que, «Una vez constituido el Consejo Escolar del centro, éste designará una persona que impulse medidas educativas que fomenten la igualdad real y efectiva entre Hombres y Mujeres». Asimismo, recoge que el Consejo Escolar «tendrá la competencia de proponer medidas e iniciativas que favorezcan la convivencia en el centro, la igualdad entre hombres y mujeres y la resolución pacífica de conflictos en todos los ámbitos de la vida personal, familiar y social».

Los desafíos recogidos en el Plan Director para la coeducación del Gobierno Vasco (2013, p.12-13) instan a:

A. Ahondar en el modelo de escuela coeducativa e introducir la perspectiva de género en la cultura y prácticas de los centros desde un planteamiento integral.

B. Orientar al alumnado a elegir su itinerario vital, académico y profesional desde la libertad, la diversidad de opciones y sin condicionamientos de género.

C. Integrar la perspectiva de género en el abordaje del fracaso escolar y garantizar que el acceso al sistema educativo sea universal, y la continuidad en este para todas las niñas y niños, teniendo en cuenta su diversidad étnica, cultural, social, económica, funcional, sexual, etc.

D. Educar para unas relaciones afectivo-sexuales y una convivencia basada en la diversidad sexual y en la igualdad de Mujeres y Hombres.

E. Prevenir la violencia de género, detectar de forma precoz los casos y prestar una atención eficaz a las víctimas, implicando de manera especial a toda la comunidad educativa.

Recientemente se ha presentado el II. Plan de Coeducación para el sistema educativo vasco, en el camino hacia la igualdad y el buen trato (2019-2023), que contiene algunos puntos novedosos interesantes. Resaltamos los ocho pilares de la coeducación:

Figura 2.

Los 8 pilares de la Coeducación

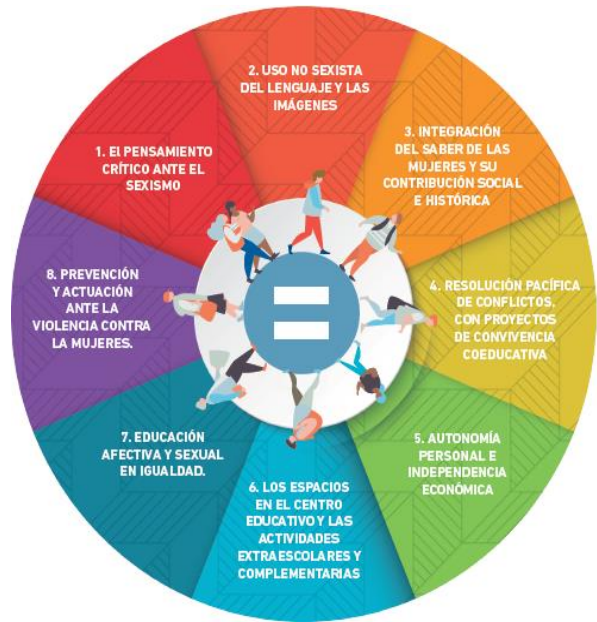

Fuente: II Plan de coeducación para el sistema educativo vasco, en el camino hacia la igualdad y el buen trato (2019-2023). 
1. El pensamiento crítico ante el sexismo.

2. Uso no sexista del lenguaje y las imágenes.

3. Integración del saber de las mujeres y su construcción social e histórica.

4. Resolución pacífica de conflictos, con proyectos de convivencia coeducativa.

5. Autonomía personal e independencia económica.

6. Los espacios en el centro educativo y las actividades extraescolares y complementarias.

7. Educación afectiva y sexual en igualdad.

8. Prevención y actuación ante la violencia contra las mujeres.

Auspiciados por el Plan, mencionar que desde el curso 2013-14 el departamento de educación convoca y subvenciona proyectos de actuación en el ámbito de la igualdad de género en las etapas de Educación Infantil, Primaria y Secundaria. Así, 176 centros públicos y 66 concertados han desarrollado y aplicado un total de 242 proyectos de coeducación y prevención de la violencia de género.

\subsection{Distribución del profesorado por etapas y sexo en la CAPV}

El Instituto Vasco de Estadística (EUSTAT), en la base de datos denominada «Personal docente en la C.A. de Euskadi por sexo, nivel, territorio histórico y titularidad. 2015/16» nos proporciona datos sobre la distribución del profesorado. Acotamos los que van desde el curso 2005-06 hasta el curso 2015-16 para analizar la evolución de la estructura de género de los centros de la CAPV. Constatamos que la distribución del profesorado por etapas se decanta por una mayoría de mujeres, sobre todo en las iniciales, más relacionadas con los cuidados. Como puede comprobarse, el porcentaje de mujeres disminuye según avanzan las etapas educativas (figura 3).

Figura 3.

Evolución del node docentes en la CAPV según etapa y sexo desde el año 2005 hasta 2016.

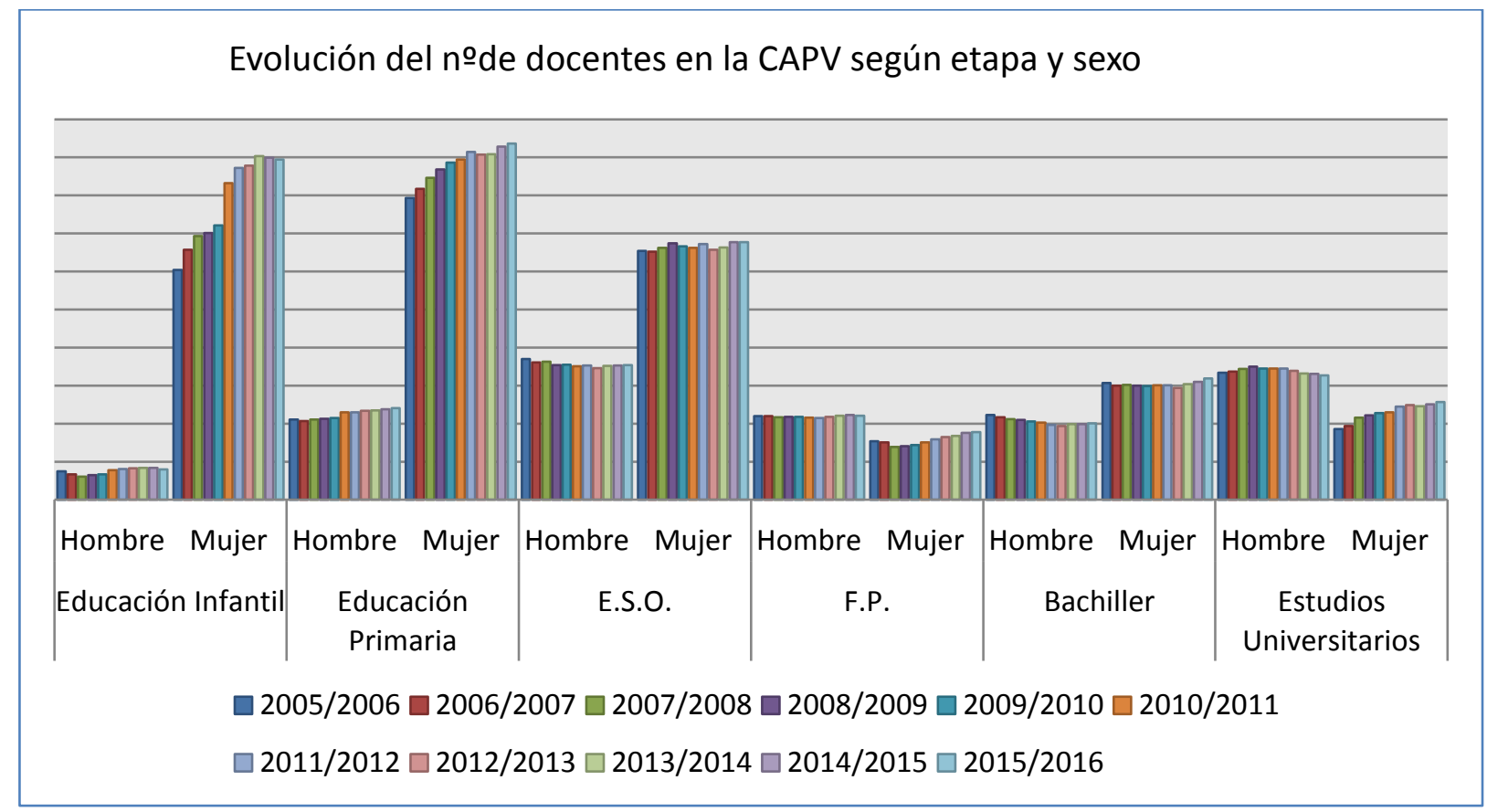

Fuente: Instituto Vasco de Estadística (EUSTAT)

\section{Método}

Este trabajo es parte de la investigación Estudio diagnóstico sobre Coeducación en los centros educativos de Vitoria-Gasteiz que ha sido llevada a cabo por el grupo de investigación IkHezi (Investigación Educativa) de la Universidad del País Vasco, a solicitud del Servicio de Educación del Ayuntamiento de Vitoria-Gasteiz. Su objeto, realizar un diagnóstico de la situación de la coeducación en los centros escolares no universitarios de la ciudad. La metodología empleada se sitúa dentro de un enfoque 
naturalista, porque se ha llevado a cabo in situ conjuntamente con las personas investigadas, es decir, con las personas pertenecientes a la comunidad escolar. Este enfoque es apropiado para investigar fenómenos sociales relacionados con las actitudes hacia ciertos temas, como es, en nuestro caso, la coeducación (Guba, 1989).

\subsection{Procedimiento}

Nuestro estudio se realizó durante el curso 2013-14 en los centros públicos, y concertados de educación obligatoria de Vitoria-Gasteiz con el fin de realizar un diagnóstico con respecto a la coeducación. Se pretendía conocer si han surtido efecto las políticas estatales, autonómicas y locales destinadas al arraigo de una cultura coeducativa en la educación formal, en qué medida son conocidas en los centros dichas políticas y, asimismo, valorar su incidencia en el día a día.

Inicialmente, se pasó un cuestionario que proporcionó una aproximación a la realidad escolar. A partir de la información recabada, se profundizó en determinadas temáticas a través de 7 grupos de discusión con profesorado, alumnado participante y sus familias.

Para la aplicación del cuestionario y la organización de los grupos de discusión, se contó con la colaboración del servicio de Educación Municipal. El pase de la encuesta se realizó en papel, sin presencia del equipo de investigación.

\subsection{Participantes}

Participaron 30 centros escolares públicos y concertados de todas las etapas no universitarias y se recogieron 419 cuestionarios, respondidos por 277 mujeres (66,1\%) y 116 hombres $(27,7 \%)$, con una edad media de 42,46 años y 17,05 años de experiencia docente.

Tabla. 1.

Número de respuestas recogidas en los cuestionarios

\begin{tabular}{lllll}
\hline \multirow{2}{*}{$\mathbf{N}^{\mathbf{0}} \mathbf{y}$ \% respuestas cuestionarios } & \multicolumn{3}{c}{ Grupos de Discusión } \\
\cline { 3 - 5 } & & Profesorado & Familias & Alumnado \\
\hline Mujeres & $277(66,1 \%)$ & 11 & 14 & 15 \\
Hombres & $120(28,6 \%)$ & 3 & 2 & 6 \\
Sin identificar & $22(5,2 \%)$ & & & 21 \\
Total & 419 & 14 & 16 & 2 \\
\hline
\end{tabular}

Fuente: elaboración propia

\subsection{Instrumentos de recogida de información}

Los cuestionarios, dirigidos a los equipos de Dirección y al profesorado de Educación Infantil, Primaria y Secundaria, se elaboraron ad hoc. Se intercalaron preguntas en las que había que elegir una opción, con otras de carácter abierto, para obtener datos sobre las políticas de igualdad y su incidencia. Se pretendía conocer cuál es la distribución del profesorado por etapas y sexo, si conocían el Plan Director para la Coeducación y la prevención de la Violencia de Género del Gobierno Vasco (2013) y la normativa referente a la figura de responsable de igualdad, si existía dicha figura en sus centros y si participaban en el Plan. Asimismo se preguntó sobre las principales acciones en favor de la igualdad impulsadas en sus centros.

Analizada la información y partiendo de las respuestas recogidas, se elaboró el guion de los grupos de discusión, que duraron aproximadamente una hora y los formaron 7-8 personas. Se debatió sobre el conocimiento y difusión de los planes de igualdad y sobre a la responsabilidad que los diferentes agentes escolares jugaban en esta difusión, así como los obstáculos con los que se encontraban. Igualmente se interpeló sobre la presencia de personas responsables de igualdad en las escuelas, su formación, sus funciones y sobre la incidencia de las políticas en el alumnado.

\subsection{Análisis de datos}

Para el tratamiento de los datos de tipo cuantitativo recogidos en los cuestionarios se ha utilizado el paquete digital SPSS 20.0. Para el análisis de la información cualitativa recogida en los cuestionarios 
y en los grupos de discusión se ha elaborado un sistema categorial (tabla 2) siguiendo criterios inductivos. Para facilitar el análisis de la información, se utilizó el programa Nvivo-12, y se organizó con una codificación axial (tabla 2).

Tabla 2.

Sistema categorial, herramienta analítica

\begin{tabular}{|c|c|c|}
\hline Categoría & Subcategoría & Descripción \\
\hline Desigualdad estructural & $\begin{array}{l}\text { Distribución profesorado por etapas } \\
\text { y por sexos }\end{array}$ & $\begin{array}{l}\text { Configuración de la plantilla } \\
\text { de los centros por sexo y } \\
\text { etapa educativa }\end{array}$ \\
\hline \multirow{5}{*}{ Políticas educativas } & Figura Responsable de Igualdad & $\begin{array}{l}\text { Se refiere a la presencia en } \\
\text { centros y formación recibida }\end{array}$ \\
\hline & $\begin{array}{l}\text { Protocolos actuación ante la violen- } \\
\text { cia de género }\end{array}$ & Existencia o no \\
\hline & \multirow{3}{*}{ Plan Director del Gobierno Vasco } & Conocimiento \\
\hline & & Participación \\
\hline & & Valoración \\
\hline \multirow[b]{2}{*}{ Proyectos coeducativos } & Conocimiento ... & Si los conocen o no \\
\hline & Participación & Grado de participación \\
\hline Días puntuales & Celebración & $\begin{array}{l}\text { Si celebran o no el } 8 \text { marzo, } \\
25 \text { noviembre... }\end{array}$ \\
\hline Influencia en el alumnado & A corto y largo plazo & $\begin{array}{l}\text { Percepción sobre la influencia } \\
\text { en el alumnado de todas estas } \\
\text { iniciativas }\end{array}$ \\
\hline
\end{tabular}

Fuente: elaboración propia

Para identificar de qué colectivo provienen las respuestas se ha establecido un código para cada participante. En los cuestionarios, el primer código binario corresponde al centro (01...); el segundo es un número otorgado a cada cuestionario por orden de recepción (...45); luego, aparece el nivel educativo (Educación Infantil EI, Educación Primaria EP, Educación Secundaria ES y Bachillerato B); después, el sexo, si es hombre $\mathrm{H}$ o mujer M. En los grupos de discusión (GD 1 a 7), la fecha y el colectivo (F familias, P profesorado, E estudiantes).

\section{Resultados}

En este apartado convergen los resultados obtenidos en los cuestionarios dirigidos al profesorado y a los equipos de dirección y también las ideas recabadas en los grupos de discusión realizados.

Se abordan la propia configuración por sexo de los equipos docentes según las diferentes etapas, la implantación de la figura responsable de coeducación e igualdad, el conocimiento de los diferentes planes o iniciativas dirigidas a conseguir la igualdad de mujeres y hombres entre los distintos colectivos y, por último, la influencia de dichos planes sobre el alumnado.

\subsection{Desigualdad estructural}

En Vitoria, según los datos recogidos en los cuestionarios, la feminización de la profesión docente es evidente en toda la Educación Obligatoria, igual que en el resto de la CAPV. En 2014 las mujeres dominaban en Educación Infantil, la etapa relacionada con los cuidados, con 216 maestras (89,25 \%) y 26 maestros. Descendían al $74 \%$ las 320 profesionales de Primaria, frente a 112 hombres. Y en Secundaria eran poco más de la mitad, 535 profesoras (55,26\%) y 433 profesores (figura 4). 
Figura 4.

Distribución del profesorado por ciclos

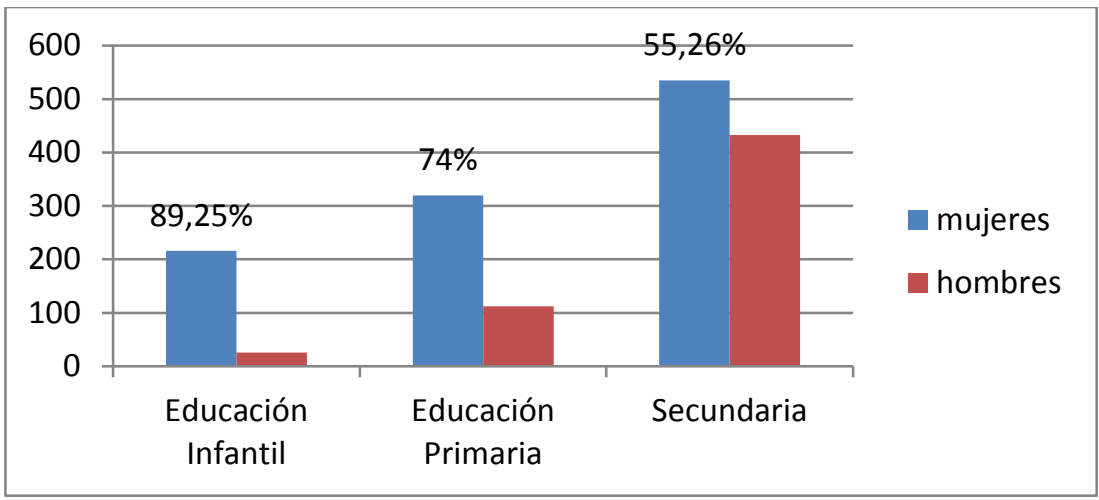

Fuente: elaboración propia

\subsection{Politicas educativas}

\subsubsection{Responsable de Coeducación en los centros y su formación}

La figura de la persona responsable de la coeducación y de la violencia de género no parece que haya encajado en la comunidad educativa vitoriana. El 48 \% de los equipos directivos afirmó contar en su centro con dicha responsable, frente al 31,69\% del profesorado. Resulta preocupante el 44,7 $\%$ que afirma no tener a nadie responsable en su escuela y el 23,58 \% que lo ignora.

Figura 5.

Presencia de la figura de responsable de coeducación

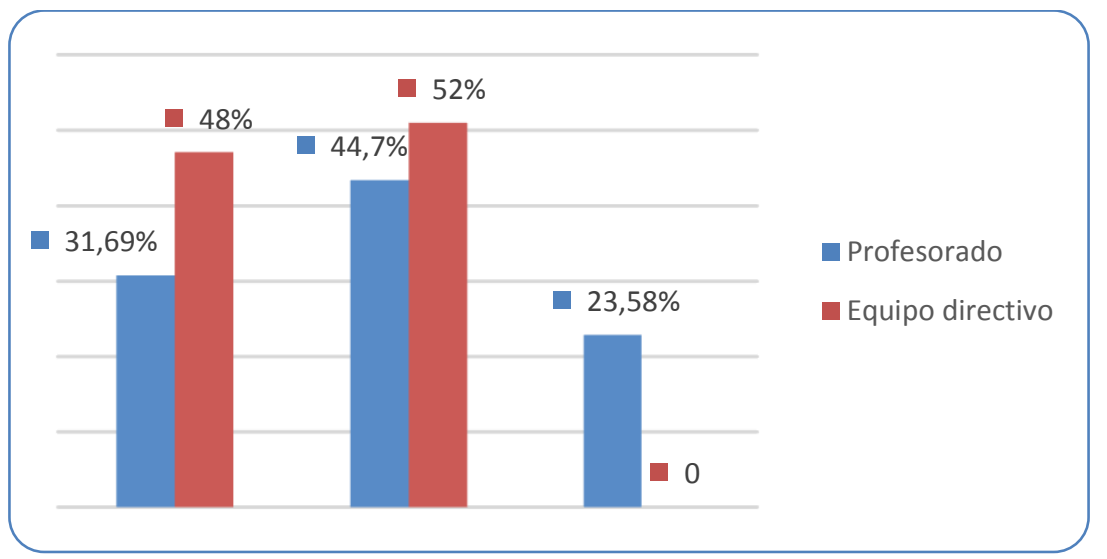

Fuente: elaboración propia

En cuanto a si esta persona responsable de la coeducación y prevención de la violencia de género recibió una formación específica, queda patente el desconocimiento del profesorado en este tema. El 60,4 \% ignoraba si esa persona recibió formación o no. Sólo el 15,6 \% respondió afirmativamente y que no, el 23,8 \%. Los equipos directivos mostraron mayor conocimiento, pues el 51,2 \% contestó positivamente. Por el contrario, el 35,8 \% aseveró que no se forman y el 12,8 \% lo desconocía. 
Figura 6.

Formación de la persona responsable de coeducación

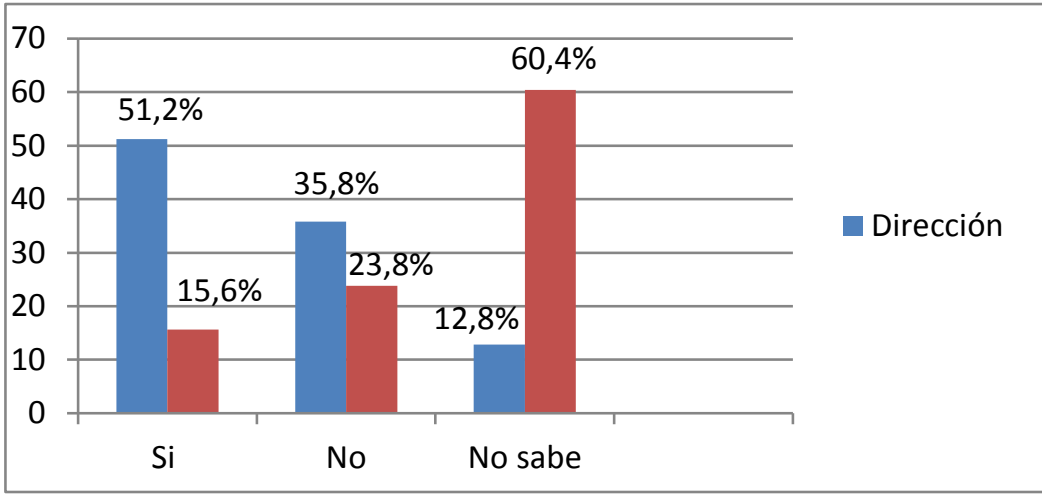

Fuente: elaboración propia

\subsubsection{Protocolos para la resolución de conflictos relacionados con temas de igualdad o violencia de género}

Únicamente el 18,18 \% manifestó tener en sus centros algún protocolo o reglamento para la resolución de conflictos ligados a la igualdad o violencia de género y el 31,81 \% dijo estar en proceso de implantación. El 50 \% de las respuestas de los equipos de dirección fueron negativas (figura 7).

Figura 7.

Existencia de protocolos de resolución de conflictos

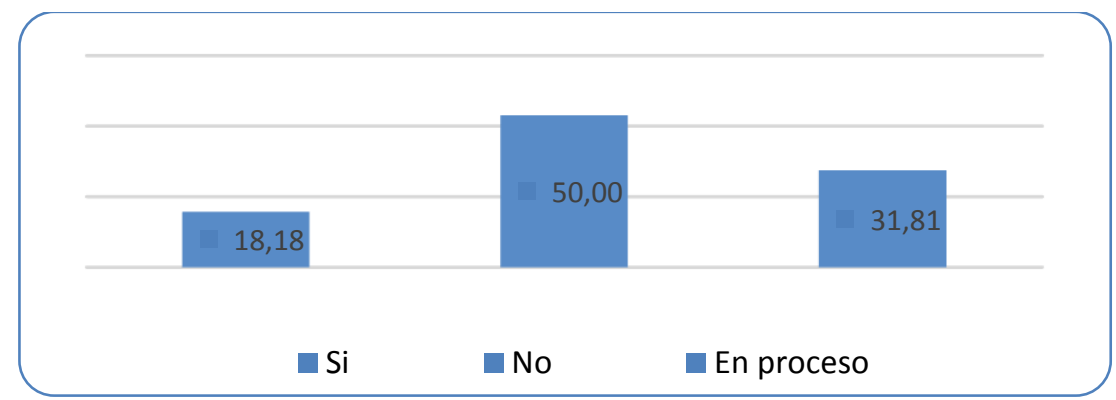

Fuente: elaboración propia

\subsubsection{Plan Director para la coeducación y prevención de la violencia de género en el sistema educativo del Gobierno V asco}

En cuanto a si conocían el Plan Director para la coeducación y prevención de la violencia de género en el sistema educativo del Gobierno Vasco (2013), según los cuestionarios, el 55 \% de las personas directivas dijo que sí; el $35 \%$, que no y el $10 \%$ no contestó (figura 8).

Figura 8.

Conocimiento del Plan de Coeducación y prevención de la Violencia de Género en el Sistema Educativo vasco por los equipos directivos

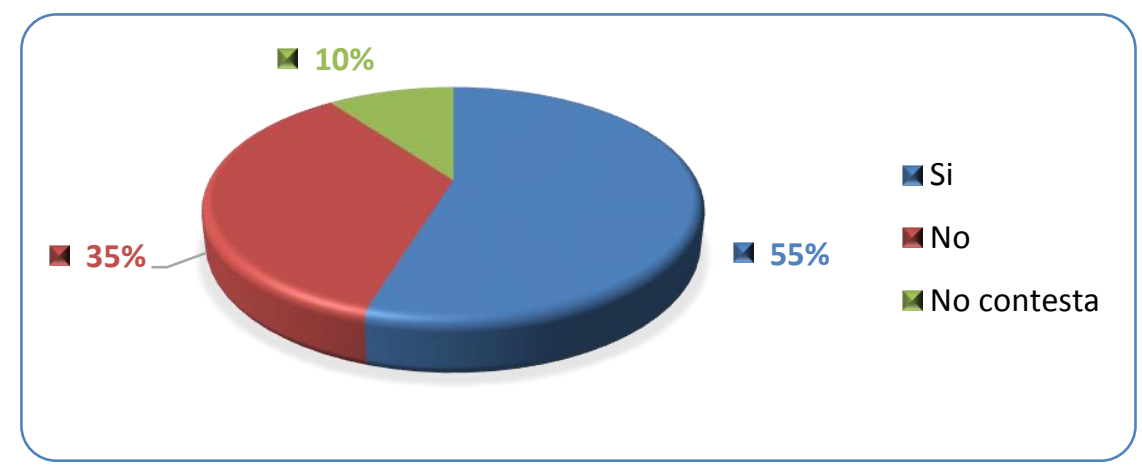

Fuente: elaboración propia 
Sin embargo, sólo el 37,3 \% del profesorado estaba al tanto y prácticamente la mitad (49 \%) ignoraba su existencia. No contestó el 13,7\%.

Figura 9.

Conocimiento del Plan de Coeducación y prevención de la Violencia de Género en el Sistema Educativo por el profesorado

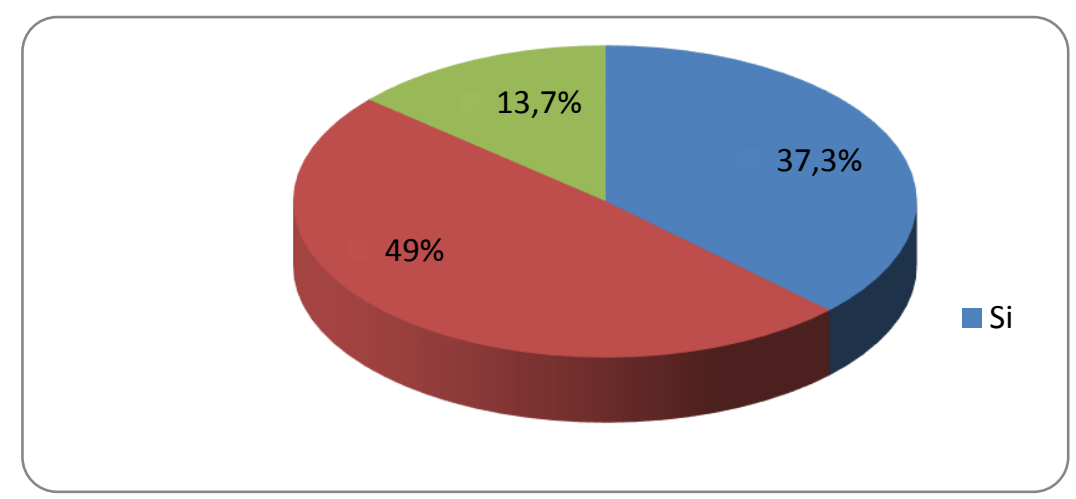

Fuente: elaboración propia

Contrariamente, quienes participaron en los grupos de discusión sabían de él y lo valoraron positivamente. Lo criticaron, porque no se requirió su participación ni se analizó, al parecer, por las prisas que acompañaron el proceso, sin las condiciones adecuadas de implantación:

«Está bien, pero no hay tiempo para interiorizar un plan nuevo.» $(0110 / / \mathrm{EP} / \mathrm{H})$

«Se ha implantado mal, apresuradamente y sin horas. Tenemos intención de aplicarlo.» $(1408 / \mathrm{ES} / \mathrm{M})$.

«El objetivo me parece buenísimo, pero no comparto la organización. La convocatoria ha llegado tarde, sin concreción. Se nos pide mucho y se nos da poco.» (1512/ES/M).

\subsubsection{Participación en la convocatoria piloto}

Las razones esgrimidas, de falta de tiempo, sobre todo, tal vez expliquen la escasa acogida de la posibilidad de participación de las escuelas en la convocatoria piloto. Sólo respondió afirmativamente el 18,7 \%, el 66,7 \% dijo que no y el 14,6 \% no contestó (figura 10).

Figura 10.

Participación en el Plan Piloto del Gobierno Vasco

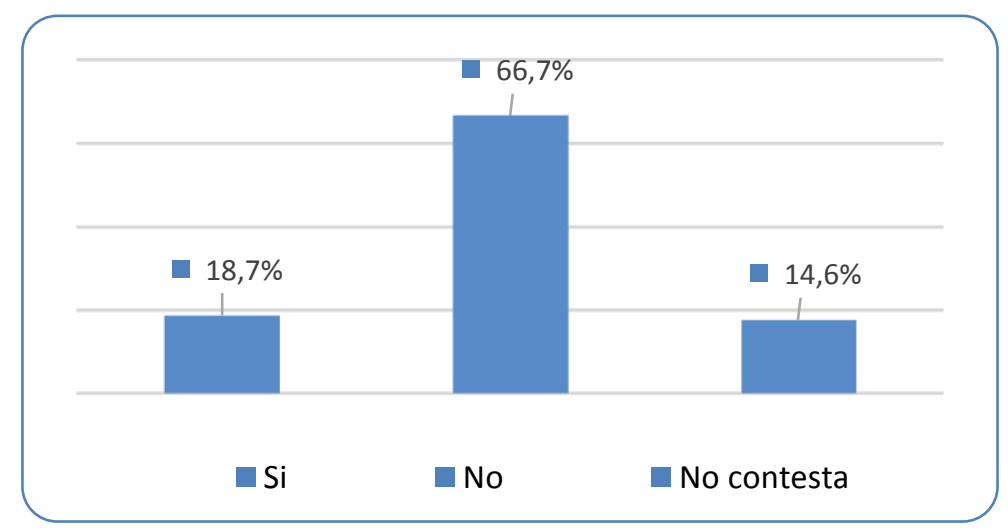

Fuente: elaboración propia

\subsubsection{Valoración del Plan}

Pese a las reticencias expresadas, el profesorado participante en los grupos de discusión consideró que el plan contribuiría a superar la idea de que el tema sólo atañe a iniciativas particulares. Y que, por su carácter institucional, incumbiría a todo el profesorado, añadiéndole valor, precisamente, su transversalidad. Deseaban que estuviera acompañado de medios materiales y económicos. 
«Por eso me parece importante el plan de coeducación aprobado recientemente por el Gobierno Vasco. No dependerá de que ciertas escuelas tengan o no sensibilidad hacia esa cuestión. Pondrán medios y también recursos económicos. Y se hará ver que debemos hacerlo, que tiene importancia y que debe influir.» (GD/140305/P/2/H)

Las ventajas que veían al plan piloto eran la seriedad y la obligatoriedad, sin supeditarse a la voluntariedad de las escuelas y los docentes. Señalaron que en las programaciones didácticas la coeducación debería estar presente. Igualmente reclamaron que, para que el plan tuviera éxito, deberían poner a disposición de las escuelas los recursos y formación necesarios, para implantarlo y garantizar su efectividad coeducadora. Señalan también la necesidad de colaboración entre las instituciones que trabajan a favor de la igualdad. Recordaron que, por ejemplo, la Administración puso gran énfasis y financiación con las TICs. E, igualmente,

«Aprovechando que ahora estamos con algún organismo [técnico del ayuntamiento], cuando quisieron poner en marcha las TICs pusieron a nuestra disposición muchísimo ímpetu y recursos. ¡A ver qué nos da la Administración! Tú, por ejemplo, has hablado de insertar la coeducación en las programaciones. Yo recuerdo cuando era obligatorio incluir las TICs en todas las unidades didácticas. Algo así. Si la Administración quiere fomentarla, debe poner recursos, énfasis, posibilidades de formarse y todo lo demás.» (GD/140305/P/1/M).

«Y, si se puede, coordinación entre instituciones.» (GD/140305/P/1/M).

En los grupos de discusión del alumnado, al hablar sobre dicho Proyecto de Coeducación, recordaron la formación realizada en torno a los malos tratos. En su opinión, la opción por la igualdad de algunos centros tiene su impacto en el profesorado. Desconocían los pormenores del mentado plan, pero se interesaron por él.

«Pues... no lo sé, aquí nos han hablado bastantes veces del mismo, pero no sabemos con certeza en qué consiste. Acabo de hablar con el profesor, porque creo que deberíamos profundizar en él.» (GD/140305/A/1/M).

\subsection{Celebración de días puntuales relacionados con el género}

Anualmente, en ciertas fechas se rememoran cuestiones relacionadas con el género, tales son el 8 de marzo (día de la mujer), 25 de noviembre (contra la violencia contra las mujeres), 17 de mayo (contra la lesbofobia, homofobia y transfobia) o 28 de junio (del orgullo gay). En las respuestas de los cuestionarios, tanto del profesorado como de las direcciones escolares, quedó patente que el 8 de marzo y el 25 de noviembre acaparan la mayoría de actuaciones, siendo testimoniales las restantes (figura 11).

Figura 11.

Actividades organizadas en los centros para la celebración de dias puntuales relacionados con el género. Respuestas del profesorado

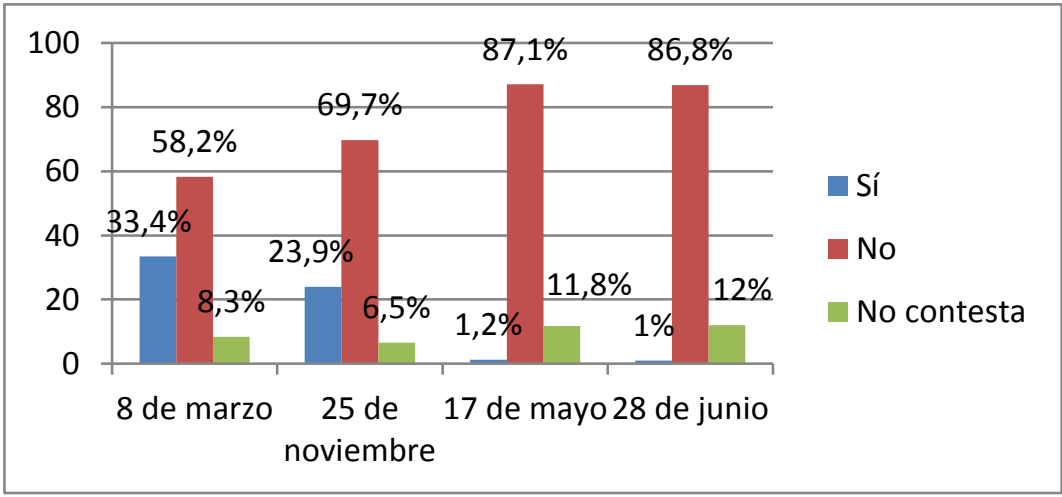

Fuente: elaboración propia

El 8 de marzo organizan mayoritariamente actividades dirigidas a la sensibilización del alumnado (tabla 3). El $50 \%$ opta por debates, World Cafés o trabajando diferentes citas o comentarios, con el fin de reflexionar sobre el sentido de ese día. 
Tabla 3.

Actividades organizadas el 8 de marzo

\begin{tabular}{ll}
\hline Actividades & Porcentaje \\
\hline Reflexiones & $50 \%$ \\
Carteles & $18,7 \%$ \\
Vídeos & $11,2 \%$ \\
Tutorías & $13,7 \%$ \\
Otras & $6,2 \%$ \\
\hline
\end{tabular}

Fuente: elaboración propia

Tampoco desdeñan las sesiones de tutoría, que alcanzan el 13,7 \% de las respuestas, decidiendo el profesorado libremente qué actividades realizar. Son algo más explícitos los grupos de discusión del profesorado, pues detallan que ese día se dedican a:

«Hablar sobre las mujeres, sobre las tareas domésticas...» (0906/EI/M)

«Lectura de información sobre este día» (1106/EP/M)

Un 18,7\% responde que, además de reflexionar o debatir sobre el tema, preparan carteles, murales o exposiciones para trabajar el 8 de marzo.

«Murales, conferencias.» $(1702 / \mathrm{B} / \mathrm{H})$

«Poemas de Carmen Gil, murales.» (2020/EP/M)

El 11,2\% del profesorado emplea vídeos, canciones y actividades lúdicas.

«Muy puntuales: vídeos, alguna canción...» (1843/ES/H)

«Otras» actividades son fruto del acuerdo del centro o del profesorado, refiriéndose, sobre todo, a las que se hacen con las niñas y niños más pequeños.

«Poner el cartel en la puerta de clase y que cada niña o niño lo dibuje y lo lleve a casa. Hablar con los niños y niñas.» $(0609 / \mathrm{EI} / \mathrm{M})$

«Leer un cuento.» (09B/EI/M)

En algunos centros se aprovecha para trabajar en los «talleres de educación para la igualdad organizados por el Ayuntamiento». (3002/B/M)

...para recordar o investigar sobre mujeres científicas...

«Se hace hincapié en las aportaciones de las mujeres a la educación y al saber en general.» $(1701 / \mathrm{ES} / \mathrm{M})$

El 25 de noviembre, día contra la violencia contra las mujeres, se organizan actividades similares a las del 8 de marzo, si bien en un número algo menor. Buscan sensibilizar y activar al alumnado, con el ánimo de reflexionar sobre el sentido de la conmemoración.

«Se comenta el día y por qué se celebra.» (3038/EP/M)

...y recordar mediante la elaboración de carteles, murales etc., su trascendencia

«Hacer carteles, exposiciones.» (1507/B/ES/H)

«Se puso un cartel en la puerta de clase para recordar la importancia de este día.» (2022/EP/M)

...también proyecciones de vídeo, actividades propuestas por iniciativa del alumnado, análisis de textos ...

«Proyección de un vídeo y trabajo sobre el mismo.» (1511/B/ES/M)

«Video: La luna en ti. Un secreto demasiado bien guardado.» (0825/EI/EP/M)

«Actividades propuestas por el alumnado.» (1820/ES/B/FP/H)

«Analizar textos.» $(2713 / \mathrm{ES} / \mathrm{H})$

...y «en otras actividades» se trabajan materiales y talleres organizados por el ayuntamiento o diversas organizaciones

«Se dio un taller con la Asociación Clara Campoamor.» (1701/ES/M)

«Diferentes actividades: world café, cine-forum... las organizadas por el Ayuntamiento.» $(1512 / \mathrm{ES} / \mathrm{M})$ 
Las respuestas que hacen referencia al 17 de mayo (contra la Lesbofobia, Homofobia y Transfobia) y al 28 de junio (Día Internacional del Orgullo LGBTI) son exiguas. Solamente se han recogido seis referencias al 17 de mayo y una, al 25 de junio, principalmente porque para esta fecha ya han finalizado las clases.

Aun siendo pocas, algunas respuestas señalan que, a su juicio, hay más iniciativas de las necesarias.

«Demasiadas.» (2408/ES/H)

...o que, a pesar de estar de acuerdo con los objetivos, consideran que añade una carga extra al trabajo.

\subsection{Valoración de las propuestas coeducativas}

Sobre la consideración que este tipo de actividades concita entre el profesorado, la mayoría está de acuerdo (49,83\%) o totalmente de acuerdo (31,5\%) en aplicar estos programas, mientras que el $7,3 \%$ se opone, porque los juzgan ineficaces. En cuanto a su efectividad en la lucha contra la discriminación, la mayoría $(68,4 \%)$ los ha valorado positivamente. Las respuestas negativas alcanzan de nuevo el $7,3 \%$ (tabla 4 ).

Tabla 4.

Nivel de acuerdo del profesorado que ha participado en programas para trabajar la coeducación

\begin{tabular}{|c|c|c|c|c|c|}
\hline Pregunta & $\begin{array}{ll}\begin{array}{l}\text { Totalmente } \\
\text { desacuerdo }\end{array} & \\
\end{array}$ & En desacuerdo & $\begin{array}{l}\text { Ni acuerdo ni } \\
\text { desacuerdo }\end{array}$ & De acuerdo & $\begin{array}{l}\text { Totalmente } \\
\text { de acuerdo }\end{array}$ \\
\hline $\begin{array}{l}\text { Es importante apli- } \\
\text { car estos programas }\end{array}$ & $5,4 \%$ & $1,92 \%$ & $11,25 \%$ & $49,83 \%$ & $31,5 \%$ \\
\hline $\begin{array}{l}\text { Estos programas } \\
\text { son efectivos en la } \\
\text { lucha contra la } \\
\text { discriminación }\end{array}$ & $4,8 \%$ & $2,5 \%$ & $21,5 \%$ & $50,8 \%$ & $17,6 \%$ \\
\hline
\end{tabular}

Fuente: elaboración propia.

Las voces recogidas en los grupos de discusión del profesorado, descubren realidades bien diferentes de unos centros a otros. Al lado de los que manifiestan haber hecho un análisis de la situación de la coeducación y puesto en marcha un proyecto coeducativo, coexisten los que sienten la coeducación como algo muy lejano, donde se trabaja de forma personal, en función de la implicación y la motivación de algún profesor o profesora concreta. En algunos casos refieren que ni siquiera se organizan actividades para la celebración de los días señalados.

«En mi centro no se hacen campañas del día de la mujer o del día de la No Violencia. Si es que es un tema que está un poco en el aire, estamos un poco así, como descoordinados. Es a nivel personal.» (GD/20140305/P/2/M).

En algunos centros ven la necesidad de estructurar el proyecto coeducativo, para ir a la raíz de los problemas, más que quedarse en las acciones puntuales que organizan en días concretos.

«Si no vamos a la raíz del asunto y decir: "Vamos a estructurar esto, y vamos a poner estas cuatro fechas concretas. Además, se lo vamos a comunicar a los Coordinadores de Etapa y ellos, a su vez, a los Tutores y se va a dedicar una hora el 8 de marzo en todas las asignaturas, o en una, en la de Tutoría.» (GD/ 140305/P/2/M).

«Que yo sepa, no vamos a hacer nada especial para este 8 de marzo. Y puede parecer un poco sorprendente, pero es que sí que se van haciendo cosas, se hacen en Bachiller, pero no está estructurado. Entonces, mira, vamos a resetear. Sabemos dónde estamos. A partir de ahí: "objetivo para este año, ya, establecer una serie de acciones concretas y que se comuniquen al Claustro". Y a partir de ahí, de direcciones pedagógicas, Coordinadores de Etapa, y transmitirlas.» $(\mathrm{GD} / 140305 / \mathrm{P} / 3 / \mathrm{H})$.

Las mismas diferencias se advierten en los grupos de discusión del alumnado. Parte del mismo señala que existe cierto activismo, pero que la educación en igualdad adolece de falta de seriedad.

«Mucho mural y mucha cosa, pero luego no hacen nada. O sea, en clase no trabajamos ese tema, por ejemplo, nosotras hasta ahora no hemos aprendido nada sobre el feminismo, ni en la ESO ni en Bachiller. Yo creo que "menos pancartitas" y más aprender cosas.» (GD/140305/A/1/M)

Por el contrario, hay otra parte del alumnado que reconoce el trabajo del profesorado, pero ignoran las campañas a favor de la igualdad más estructuradas 
«En el Instituto hacemos actividades, además, este año y el año pasado hemos trabajado mucho este tema y el profesorado ha hablado mucho sobre esto. Hemos hecho danzas y cosas así.» (GD/ $140403 / \mathrm{A} / 2 / \mathrm{M})$.

Las familias corroboran que en los centros se trabaja la coeducación, según la voluntad del profesorado.

«Yo creo que se trabaja en general de forma transversal en los centros, o sea, se trabaja en todas las asignaturas, se trabaja... depende de la implicación de cada centro y de cada profesor, se trabaja de una manera transversal, que yo creo que está muy bien, pero que también corres el riesgo de que se diluya, y de que no se trabaje de una manera específica, que (...) queda un poco en manos de todo el profesorado del centro, al final no haya nadie que trabaje solo eso o que tome la iniciativa en esas cosas (...) A no ser que sean actividades específicas.» (GD/ 140319/F/2/M)

Algunas de las personas participantes consideran que la escuela, como institución, no es coeducativa. Opinan que se ocupan, sobre todo, en Educación Infantil, porque posteriormente se da más importancia a las materias y a los resultados académicos. Subrayan que hay que empezar cuanto antes, ya que en la ESO comienzan a aparecer indicios de sumisión en las parejas.

«El modelo de escuela que tenemos no es coeducativo. Yo creo que, en mi colegio, en Infantil (...) se lo curran mucho más. Ya cuando empiezan en Primaria relajan mucho más la historia, pero en Infantil yo creo que van a por ello. Luego ya en Primaria empiezan con materia y al final solo tienen una hora de tutoría o dos a la semana y entonces, tampoco.» $(\mathrm{GD} / 140319 / \mathrm{F} / 2 / \mathrm{M})$

«Yo lo que veo fundamental es trabajarlo desde Infantil, porque si es cierto que luego llegan a la ESO y suceden cosas como (...) que llegan y dicen de su novio “jjo! ¡Fíjate cuántos mensajes me ha mandado!” “ijo!, es que, fijate ¡cuánto me quiere!”... iperdona!, eso no es querer, ahí te están controlando... Pero ellas lo viven como con ilusión y eso es terrible, y cuanto antes se trabaje eso mucho mejor.» (GD/ 140319/F/2/M)

\subsection{Incidencia de los diferentes planes e iniciativas en el alumnado}

Obviamente el fin último de los distintos planes e iniciativas es inculcar al alumnado «el camino hacia la igualdad y el buen trato», de acuerdo al II Plan de Coeducación para el sistema educativo vasco, presentado recientemente (Bilbao, 6 y 7 de marzo de 2019). Pero no toda la comunidad educativa es unánime en sus apreciaciones.

De los docentes que respondieron al cuestionario, el $49 \%$ afirmó que influían positivamente y sólo el 12,3\%, que no. Llama la atención, por lo abultado, el dato del 28,7 \% \% que dice que nunca interviene en la escuela y un $10 \%$ que desconoce si se ha implementado algún programa en concreto.

Figura 12

Incidencia de los planes en el comportamiento del alumnado

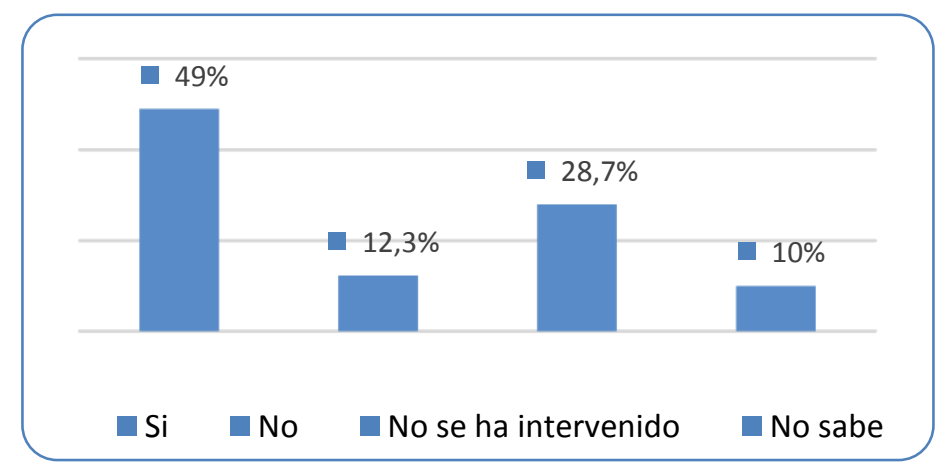

Fuente: elaboración propia

En las respuestas afirmativas de los grupos de discusión del profesorado sobresalen las opiniones que recalcan la sensibilización y concienciación que calan entre la juventud.

«Piensan más, se les ve más concienciados.» (1512/ESO/M) 
«Sí, creo que se consigue una mayor sensibilización y algunas ideas se les transmiten con más claridad.» $(1510 / \mathrm{B} / \mathrm{H})$

Asimismo, advierten que la influencia de dichos programas no es inmediata, sino transcurrido un tiempo.

«Algo, sí; se les invita a reflexionar y éste es el paso previo a la acción.» (1830/B//ESO/M)

«Sin ninguna duda. Aunque ahora, a medio plazo, no lo veamos, lo llevan dentro y ya lo sacarán.» $(1837 / \mathrm{ES} / \mathrm{M})$

«Ésa es la experiencia. Si la influencia no es inmediata, trabajamos con la esperanza de que "algo" les quedará.» (2213/ES/M)

En contraposición con estas opiniones hay voces que piensan que el tiempo puede jugar en su contra:

«Sobre todo, los chicos. Se conciencian y sus actitudes ante las chicas cambian, son más positivas. Por desgracia, no parece que sea algo duradero.» (1503/ES/H)

«Quizá, al principio. Luego, cuando el tiempo corre, las cosas vuelven a la "normalidad".» $(2610 / \mathrm{ES} / \mathrm{H})$

Indican que su eficacia puede verse afectada por su vida fuera de la escuela, recordando que la responsabilidad también concierne a las familias e, incluso, a la sociedad.

«Ś́, estos programas creo que son muy válidos y, aunque su influencia sea más o menos intensa, deben mantenerse. Creo, sin embargo, que el contexto en el que se mueven fuera es más efectivo, para mejor o para peor.» $(3009 / \mathrm{B} / \mathrm{ES} / \mathrm{H})$

Otra parte del profesorado recela de la eficacia de estas políticas y de si la prevención de la violencia compete o no a la escuela.

«No, los programas implementados en los colegios no tienen ninguna influencia en el alumnado.» $(3024 / \mathrm{EP} / \mathrm{H})$

«A tenor de lo que comentan, no aprenden nada nuevo.» (3007/ES/B/M)

«No es un problema en el centro y, por ello, no se ve la necesidad de hacer más.» (2410/ES/H)

El alumnado neutraliza la percepción negativa expresada por parte del profesorado. Preferiría una mayor difusión de los proyectos coeducativos, para que lleguen a todos los docentes, porque parece que solo compete a algunas profesoras voluntariosas.

«Yo creo que el proyecto coeducativo debería publicitarse más, porque en el instituto pocos saben que estamos inmersos en un proyecto coeducativo. Y debería saberse más, concretar lo que es..., Nosotras damos Psicología y la profesora se preocupa, pero yo creo que todo el mundo no lo sabe. Por ejemplo, cuando lo presentaron en el Consejo Escolar, no se lo explicaron bien a todos los padres y madres y al profesorado.» (GD/140305/A/1/M)

Pese a las dificultades, constatan que, gracias a esos programas, son conscientes de la importancia de defender los derechos de las mujeres, de favorecer la igualdad y de que aún hoy la mujer es discriminada.

«Tener los mismos derechos, que de siempre la mujer ha sido oprimida y que eso es lo que hemos sufrido desde pequeñas. Quedarnos con lo importante, para defender nuestros derechos. Que hemos recibido esas ideas de nuestros padres y de la sociedad, que somos inferiores, que nos tienen que proteger. En esta escuela se tratan estos temas, porque participamos en un proyecto coeducativo del Gobierno Vasco. También hemos aprendido que no hay igualdad en los malos tratos, lo hemos aprendido de distintas vías.» (GD/140305/A/1/M) 
Tabla 5.

Resumen de resultados

\begin{tabular}{|c|c|}
\hline Categoría & Respuestas condensadas \\
\hline $\begin{array}{l}\text { Distribución del profesorado por sexos } \\
\text { en los distintos niveles educativos }\end{array}$ & $\begin{array}{l}\text { Profesión docente feminizada, mucho más acentuada cuanto más } \\
\text { joven es el alumnado. }\end{array}$ \\
\hline $\begin{array}{l}\text { Responsable en coeducación y pre- } \\
\text { vención de la violencia de género }\end{array}$ & La mitad de las escuelas participantes cuenta con su figura \\
\hline Formación específica en el tema & $\begin{array}{l}\text { El profesorado y los equipos directivos desconocen si la persona } \\
\text { responsable recibe alguna formación. } \\
\text { El claustro no asume que dicha formación le competa. Cuando hay } \\
\text { ocasión, sólo asisten } 1 \text { ó } 2 \text { personas. }\end{array}$ \\
\hline $\begin{array}{l}\text { Plan Director para la coeducación y } \\
\text { prevención de la violencia de género } \\
\text { en el sistema educativo del Gobierno } \\
\text { Vasco (2013) }\end{array}$ & $\begin{array}{l}\text { Más de la mitad de las escuelas lo conocen. De estas, la mitad no lo ha } \\
\text { analizado y, menos aún, están dispuestas a participar en él. Pese a } \\
\text { mostrarse de acuerdo con sus objetivos, discrepan de su puesta en } \\
\text { marcha. }\end{array}$ \\
\hline Celebración de días puntuales & $\begin{array}{l}\text { Constituyen los hitos de la coeducación en los centros. Aun así, no en } \\
\text { todos los centros se está de acuerdo en celebrarlos. } \\
\text { Más allá de campañas y celebraciones, se plantea la necesidad de pro- } \\
\text { yectos globales de centro. }\end{array}$ \\
\hline $\begin{array}{l}\text { Influencia de esas políticas en el } \\
\text { alumnado }\end{array}$ & $\begin{array}{l}\text { La mayoría del profesorado comparte la idea de que contribuyen } \\
\text { positivamente. Casi un tercio estima que no han hecho nada en ese } \\
\text { campo. }\end{array}$ \\
\hline
\end{tabular}

Fuente: elaboración propia

\section{Conclusiones}

Algunas investigaciones educativas han puesto de manifiesto que la desigualdad sexual no ha desaparecido de la institución escolar, sino que se ha transformado hacia nuevas formas, tal vez más sutiles (Arenas, 2006; Madrid \& Lucer, 2010; Tomé y Rambla, 2001). A pesar de ello, la coeducación no constituye una prioridad en la escuela, que es la principal destinataria de propuestas procedentes de instituciones diversas y, con frecuencia, depende de la implicación de cada centro y de cada docente.

Es de reseñar que, fruto de las políticas instauradas en las escuelas de Vitoria para incidir en la coeducación y la prevención de la violencia de género, la mitad de las mismas cuentan con personal especializado en la materia. A juicio de los equipos de dirección, dicho personal ha recibido una formación especializada, pero la mayor parte del profesorado lo desconoce. También el alumnado.

Por lo tanto, el profesorado no está debidamente informado sobre la presencia y formación recibida por la persona responsable de coeducación y prevención de la violencia de género en los centros y, en menor medida, tampoco lo están los equipos de dirección.

Existen, pues, deficiencias en los canales de información entre los distintos miembros de la comunidad escolar. Son indispensables puentes que hagan de enlace entre los padres y madres, alumnado, profesorado, equipos de dirección. Se precisan acciones que tengan en cuenta a toda la comunidad, urge una labor de colaboración entre diferentes.

El profesorado conoce los programas y planes vigentes que, a su juicio, no tienen el impacto deseado. Las dificultades son muchas y diversas. Entre la variedad de proyectos que llegan a la escuela, la coeducación es uno de tantos y no se considera primordial en muchos centros; se actúa por modas, sustituyéndose sin mucho criterio unas propuestas por otras, sin una evaluación efectiva.

Aun así, ha quedado patente la necesidad e interés de una gran parte del profesorado en la implementación de las políticas de igualdad en los centros (Azorín, 2014), aunque, por otra parte, se ve que necesitan una mejor coordinación para llevar los proyectos adelante. En este sentido, el profesorado considera que la obligatoriedad del Plan del Gobierno Vasco contribuye a superar la idea de que la coeducación depende de implicaciones personales y que la figura responsable de igualdad en los centros puede ser fundamental. 
Para avanzar en la escuela coeducativa, el profesorado señala que es necesario diseñar proyectos globales que impulsen la formación en género, introducción de la perspectiva de género en el curriculum y la elección y preparación de materiales adecuados para trabajar diferentes aspectos (Tomé, 2017, Subirats, 2016).

Para ello, la colaboración entre instituciones es esencial. Se pide una coordinación efectiva al proponer iniciativas o planes. Deben tejerse redes para compartir recursos entre los distintos agentes intervinientes.

Urge trabajar al unísono, para que los mensajes sean inequívocos y efectivos.

En resumen, en relación a los proyectos coeducativos, actividades, acciones o proyectos que se llevan a cabo en los centros, se pueden definir tres modalidades de centros, según la fase en la que se encuentran:

Primera fase) La coeducación está muy lejos de las preocupaciones o prioridades del profesorado; centros con un nivel de implicación muy pequeño.

Segunda fase) Centros que participan en campañas y acciones puntuales, pero que sienten la necesidad de estructurar el trabajo relacionado con la coeducación.

Tercera fase) Centros involucrados con la coeducación y que participan en el programa piloto del Gobierno Vasco.

\section{Referencias}

Arenas, G. (2006). Triunfantes perdedoras. La vida de las niñas en la escuela. Barcelona: Graó.

Aristizabal, P. (2011). Emakume eta gizonen berdintasuna irakasleen formazioan: Gasteizko Irakasle Eskolaren kasua (tesis doctoral). UPV/EHU: Vitoria-Gasteiz. Recuperada de: http://www.euskara.euskadi.net/appcont/tesisDoctoral/PDFak/Pilar_Aristizabal_TESIA.pdf

Azorín, C. M. (2014). Actitudes del profesorado hacia la coeducación: claves para una educación inclusiva. ENSAYOS, Revista de la Facultad de Educación de Albacete, 29(2).

Barbieri, D., Franklin P., Janeckova H., Karu M., Lelleri R., Riobóo Lestón I., Luminari D., Madarova Z., Maxwell K., Mollard B., Osila L., Paats M., Reingarde J., \& Salanauskaite L. (2017). Gender Equality Index 2017: Measuring gender equality in the European Union 2005-2015 - Report. European Institute for Gender Equality. Luxembourg: Publications Office of the European Union. Recuperado de: at: https://eige.europa.eu/sites/default/files/documents/20177277_mh0517208enn_pdf.pdf

Calatrava, M. A. (2013). Políticas públicas de igualdad en el ámbito de la educación. Balance actual y retos futuros. Profesorado. Revista de Curriculum y Formación del Profesorado, 17(1), pp. 9-27.

Consejería de Educación y Cultura del Gobierno del Principado de Asturias (2019). Red telemática Coeducación. Espacio para educar en la igualdad. Obtenido en: https://www.educastur.es/igualdad

Consejería de Educación y Universidades. Gobierno de Canarias. (2018). Programa educar para la igualdad. Obtenido en: http://www.gobiernodecanarias.org/educacion/web/programas-redeseducativas/programas-educativos/educa-igualdad/

Departament d'Educacio. Generalitat de Catalunya (2019). Coeducació i Igualdat de género. Recursos telemáticos en de coeducación. Obtenido en: http://xtec.gencat.cat/ca/curriculum/coeducacio/

España. Tribunal Constitucional (Sección del Tribunal Constitucional). Sentencia 31/2018, de 10 de abril de 2018. BOE, $\mathrm{n}^{\circ}$ 124, de 22 de mayo de 2018, pp. 53548-53638.

Eustat - Euskal Estatistika Erakundea - Instituto Vasco de Estadística. (2019). Datos estadísticos de la C.A.de Euskadi. www.eustat.eus. 
García, R. (2012). La educación desde la perspectiva de género. Ensayos, Revista de la Facultad de Educación de Albacete, 27, pp. 1-18.

Gobierno de Navarra. (2017). El Plan de Coeducación 2017-20121 para los centros y comunidades educativas de Navarra. Obtenido en: http://coeducando.educacion.navarra.es/programa-coeducando/

Gobierno Vasco. (2013). Plan Director para la coeducación y la prevención de la violencia de género en el sistema educativo. Vitoria-Gasteiz: Servicio Central de Publicaciones del Gobierno Vasco.

Gobierno Vasco. (2019). II Plan de coeducación para el sistema educativo vasco, en el camino hacia la igualdady el buen trato (2019-2023). Vitoria-Gasteiz: Servicio Central de Publicaciones del Gobierno Vasco.

Grañeras, M., Mañeru, A., Martín Sánchez, R., De La Torre, C., \& Alcalde, A. (2007). La prevención de la violencia contra las Mujeres desde la educación: investigaciones y actuaciones educativas públicas y privadas. Revista de Educación, 342, pp. 189-212.

Guba, E. G. (1989). Criterios de credibilidad en la investigación naturalista. En: J. Gimeno Sacristán, \& A. I. Pérez-Gómez (Ed.). La enseñanza: su teoría y su práctica, 3. ed. (pp. 148-165). Madrid: Akal.

Ibañez, P. (2014). La figura responsable de igualdad en los consejos escolares de los centros educativos en las diferentes comunidades autónomas (Trabajo de Fin de Grado). Universidad de la Rioja, La Rioja.

Ikertalde Grupo Consultor. (2014). VI Plan de Igualdad para la igualdad de Mujeres y Hombres en la CAE. Vitoria-Gasteiz: Emakunde-Instituto Vasco de la Mujer.

Informe GENET (2015). Género y políticas públicas: claves para la agenda política. Madrid: CSIC, Centro de Ciencias Humanas y Sociales.

Instituto de la Mujer (2019). Portal Intercambia. Recursos telemáticos del ámbito coeducativo. Recuperado de: http://intercambia.educalab.es/

Ley 1/2004, de 28 de diciembre, de Medidas de Protección Integral contra la Violencia de Género. BOE núm 313, de 29 diciembre 2004.

Ley 4/2005, de 18 de febrero, para la Igualdad de Mujeres y Hombres. BOPV núm 42, 02 de marzo de 2005.

Ley Orgánica 2/2006, de 3 de mayo, de Educación (LOE). BOE núm. 106, 4 de mayo de 2006.

Ley Orgánica 8/2013 de 9 de diciembre, para la Mejora de la Calidad Educativa (LOMCE). BOE núm. 295, de 10 de diciembre de 2013.

Lorenzo, M., Sola, T., \& Cáceres, M. P. (2007). Principales referentes legales y educativos para el desarrollo de la coeducación. Publicaciones de la Facultad de Educación y Humanidades del Campus de Melilla, 37, pp. 73-87.

Madrid, J. M., \& Lucer, L. A. (2010). Directrices de la política educativa de género en España (1970-2010). Educatio Siglo XXI, 28, pp. 223-244.

Roset, M., Páges, E., Lojo, M., \& Cortada, E. (2008). Guia de coeducació per als centres educatius: pautes de reflexió i recursos per a l'elaboració d'un projecte de centre. Barcelona: Institut Català de les Dones.

Suberviola, I. (2012). Coeducación: un derecho y un deber del profesorado. Reifop. Revista Electrónica Interuniversitaria de Formación Del Profesorado, 15(3), pp. 59-67. 
Subirats, M. (2014). Avances y retos en las políticas y en las prácticas de los géneros. Educar, 50(1), pp. 85-100. https://doi.org/10.5565/rev/educar.692

Subirats, M. (2016). De los dispositivos selectivos en la educación: el caso del sexismo. Revista de la Asociación de Sociología de la Educación (RASE), 9(1), pp. 22-36.

Tomé, A. \& Rambla, X. (Ed.) (2001). Contra el sexismo. Coeducación y democracia en la escuela. Barcelona: Síntesis-UAB.

Tomé, A. (2017). Estrategias para elaborar proyectos coeducativos en las escuelas. Atlánticas-Revista Internacional de Estudios Feministas, 2(1), pp. 89-116. https://doi.org/10.17979/arief.2017.2.1.1979

Torres, L., \& Miguel, S. (2010). Nuevos retos para la escuela coeducativa. Iniciativas y experiencias para la prevención de la violencia de género. Tabanque Revista Pedagógica, 23, pp. 15-44.

Urruzola, M. J. (1995). Introducción a la filosofía coeducadora. Bilbao: Maite Canal. 